death. The enabling quality of this discussion helped them to "make the most of the limited time left."

Parents vividly remembered the doctor's response to their distress. The doctor's ability to accept and understand the parents' grief was important in establishing trust and shaping the future relationship. Feelings of anger, guilt, and sadness are well known to be part of the process of grieving, which may begin at the time of diagnosis when the fatal nature of the illness is confirmed. ${ }^{1 .}$ Parents may need help to work through their anger and sadness during this long and necessary grieving process. Schoenberg pointed out that "health professionals place great emphasis on the preservation of life and in general view the patient's death as a personal failure." And yet the physician is required to be "honest, consistent, supportive and sympathetic while maintaining the qualities of equanimity and imperturbability." The results of our study confirm that when the doctor showed these qualities when imparting the diagnosis of a life threatening illness it in fact sustained and supported the parents despite their deep distress, and the beneficial effects persisted, in some cases for many years.

We thank the families who so generously participated in the study; all who helped with the recruitment including the staff of Helen House Hospice; the many paediatric consultants; Dr Roger Burne; Carolyn Fordham Walker, Ann Day, and Pavlos Anastasiades for unstinting help; and Dr C Ounsted for comments on an earlier draft of the paper. The study was funded by the DHSS, The King Edward Hospital Fund and Help the Hospices.
1 Fulton B, Gottesman DJ. Anticipatory grief; a psychosocial concept reconsidered. Br f Psychiatry 1980;137:45-54.

Bozeman MF, Orbach CE, Sutherland AM. Pswchological impact of cancer and its treatment Cancer 1955:8:1-9.

3 Quine J, Pahl J. First diagnosis of severe mental handicap: characteristics of unsatisfactory encounters between doctors and parents. Soc Sci Med unsatisfactory

4 Greenberg LQ. Jewett LS, Gluck RS, et al. Giving information for a life threatening diagnosis: parents' and oncologists' perceptions. Am $\mathcal{F}$ Dis Child 1984:138:649-53.

5 Mulhern R, Crisco J, Camitta B. Patterns of communication among pediatric patients with leukemia, parents, and physicians: prognostic disagreements and misunderstandings. F Pediatr 1981;99:480-3.

6 Cunningham CC, Morgan PA, McGucken RB. Downs syndrome: is dissatisfaction with disclosure of diagnosis inevitable? Dev Med Child Neurol 1984;26:33-9

7 Sherman MD, Austrian RW, Shapiro T. Labeling and unlabeling: perception of diagnostic terms among mothers and professionals. I Dev Behav Pediat 1981;2:93-6.

8 Rockowitz RJ, Davidson PW. Discussing diagnostic findings with parents. Journal of Learning Disabilities 1979;12:11-6.

9 Koch CR, Hermann J, Donaldson $\mathrm{MH}$. Supportive care of the child with cancer and his family. Semin Oncol 1974;1:81-6.

10 Myers BA. The informing interview, enabling parents to "hear" and cope with had news. Am 7 Dis Child 1983:137:572-7.

11 Kaplan D, Grobstein R, Smith A. Predicting the impact of severe illness in families. Health Soc Work 1976;1:71-82.

12 Findlay II, Smith P, Graves PJ, Linton ML. Chronic disease in childhood: a study of families' reactions. British fournal of Medical Education 1969;3 66-9.

13 Wiener JM. Reactions of the family to the fatal illness of a child. In Schoenberg B, Carr AC, Peretz D, Kutscher AH, eds. Loss and grief: psychological management and medical practice. New York: Columbia University Press, 1970:87-101

14 Firth M. Diagnosis of Duchenne muscular dystrophy: experiences of parents of sufferers. Br Med f 1983;286:700-1.

15 Teasdale JD. Negative thinking in depression: cause, effect or reciprocal relationship? Advances in Behavior Research and Therapy 1983;5:3-25.

16 Goldberg D. The detection of psychiatric illness by questionnaire. Oxford: Oxford University Press, 1972.

17 Schoenberg B. Management of the dving patient. In: Schoenberg B, Carr AC Peretz D, Kutscher $\mathrm{AH}$, eds. Loss and grief: psychological management and medical practice. New York: Columbia Úniversity Press, 1970:238.

(Accepted 31 March 1989)

Lesson of the Week

\title{
Unrecognised high pressure chronic retention of urine presenting with systemic arterial hypertension
}

\author{
R R Ghose, V Harindra
}

Men over 50 with hypertension of recent onset should be investigated for high pressure chronic retention of urine

Singleton Hospital, Sketty, Swansea SA2 8QA R R Ghose, FRCP, consultant physician V Harindra, MRCP, medical registrar

Correspondence to: $\mathrm{Dr}$ Ghose.
Clinical and urodynamic assessment of chronic retention of urine shows that the condition may be subdivided into three categories. These are, firstly (80$85 \%$ of patients), low pressure chronic retention characterised by low bladder filling pressure and high voiding pressure from powerful destrusor activity, typically associated with bladder outlet obstruction from prostatic hypertrophy; secondly $(15 \%$ of patients), low pressure chronic retention with low bladder filling pressure and low voiding pressure from bladder hypotonia and weak detrusor activity; and, thirdly (about 5\% of patients), high pressure chronic retention with high pressure voiding arising from bladder outflow obstruction accompanying benign prostatic hypertrophy, prostatic carcinoma, bladder carcinoma, urethral strictures, and urethral valves.

High pressure chronic retention is important because of its tendency to produce uraemia and hypertension as a consequence of bilateral hydronephrosis. In contrast with low pressure chronic retention urological symptoms may be absent in advanced disease. In some cases late onset enuresis and a tense, painless bladder may be present. ${ }^{2}$ In a recent study $52 \%$ of patients with untreated high pressure chronic retention presenting to a urological clinic were noted to have diastolic blood pressures ranging from 95 to $120 \mathrm{~mm}$ $\mathrm{Hg}$. Bladder drainage for three days produced an increase in urine volume and sodium excretion with a fall in body weight accompanied by a reduction in diastolic blood pressure to $70-100 \mathrm{~mm} \mathrm{Hg}$. It was concluded that high pressure chronic retention may represent the commonest form of surgically correctable hypertension.

We describe six men who presented with moderate to severe hypertension, some of whom were resistant to antihypertensive drugs, and who were found to have high pressure chronic retention of urine. The effects of transurethral resection of the prostate on hypertension and renal function are examined.

\section{Patients and methods}

Six men aged 50-70 years (mean 62) were referred to a medical clinic because of hypertension. None complained of urological symptoms but questioning elicited a history of late onset enuresis for the past three months in two (cases 4 and 6). Both patients were found to have tense, painless bladders on palpation of the suprapubic region. Rectal examination disclosed a prostate of normal size and consistency in five patients, the remaining patient (case 3 ) having moderate enlargement.

Biochemical screening disclosed serum creatinine concentrations ranging from 133 to $409 \mu \mathrm{mol} / \mathrm{l}$ (mean 291). Imaging was performed with urinary tract ultrasonography, intravenous urography, and gammacamera renography. Full urological assessment was obtained. Glomerular filtration rate and effective renal plasma flow were estimated by standard isotope techniques. ${ }^{+}$Blood pressure was measured with a mercury 
sphygmomanometer, diastolic pressure being recorded at phase $\mathrm{V}$.

\section{Results}

All six patients fulfilled the criteria for a diagnosis of high pressure chronic retention of urine. ${ }^{2}$ Ultrasonography of the urinary tract showed gross bilateral hydronephrosis and hydroureter in all patients, confirmed by intravenous urography. Renographic findings were not diagnostic, however, because of a severely diminished glomerular filtration rate and effective renal plasma flow at the time of initial examination. Examination of a midstream specimen of urine showed no evidence of infection.

Table I gives the clinical features, details of antihypertensive drugs used, and the effect of transurethral resection of the prostate on diastolic blood pressure. Table II shows the changes in the serum creatinine concentration, glomerular filtration rate, and effective renal plasma flow after surgery. The patient in case 1 , who received no antihypertensive drugs before or after transurethral resection of the prostate, had his plasma renin activity measured preoperatively and three months after operation. Before surgery the plasma renin activity was $5.67 \mathrm{nmol} / \mathrm{h} / 1$ recumbent and $9 \cdot 18$ $\mathrm{nmol} / \mathrm{h} / \mathrm{l}$ ambulant and three months after surgery 3.07 $\mathrm{nmol} / \mathrm{h} / \mathrm{l}$ recumbent and $3.97 \mathrm{nmol} / \mathrm{h} / \mathrm{l}$ ambulant (normal ranges: recumbent $1 \cdot 2-2 \cdot 4 \mathrm{nmol} / \mathrm{h} / \mathrm{l}$, ambulant $3 \cdot 0-4 \cdot 3 \mathrm{nmol} / \mathrm{h} / \mathrm{l})$.

Histologically prostatic tissue obtained at transurethral resection showed benign prostatic hypertrophy in all cases.

\section{Discussion}

These six patients were referred to hospital with a diagnosis of essential hypertension, but investigation disclosed the presence of secondary hypertension due to high pressure chronic retention. Renal function was severely impaired in all cases, and this was reflected in the raised serum creatinine concentration and diminished glomerular filtration rate and effective renal plasma flow. Possibly high pressure chronic retention had been present for a long period before diagnosis. In three patients hypertension had been recognised and treated for several years before the diagnosis was established, but in three others hypertension was of short duration, suggesting that raised blood pressure occurs late in high pressure chronic retention. Continued deterioration of renal function is inevitable in patients whose hypertension is controlled by antihypertensive drugs. The raised serum creatinine concentration suggested the need for urinary tract imaging, which showed bilateral hydronephrosis and hydroureter, though obstructive nephropathy may occur without dilatation of the upper urinary tract. ${ }^{5}$ The cause of bladder outflow obstruction was found to be benign prostatic hypertrophy, but malignancy of the prostate or bladder may sometimes be responsible. ${ }^{\circ}$

Once a diagnosis of high pressure chronic retention has been made it is essential to obtain surgical relief of bladder outflow obstruction to prevent further renal damage and to treat the hypertension. Raised blood pressure fell to normal within days of transurethral resection of the prostate, so that existing antihypertensive drug treatment could be discontinued. Postobstructive natriuresis may have accounted for this fall in blood pressure, ${ }^{3}$ implying that the hypertension was mediated by sodium or volume overload. The patient in case 1 , however, showed a high renin state. Belman et al reported that in unilateral hydronephrosis with renal-pressor hypertension raised renin activity was present in renal vein blood from the obstructed kidney and that after relief of obstruction there was a fall in blood pressure and renal vein renin concentration to normal. ${ }^{7}$ Repeat measurement of plasma renin activity three months after surgery when our patient was normotensive showed a definite fall in this value, though it remained slightly higher than the normal reference range in the recumbent position. Inappropriate plasma renin activity relative to sodium handling may be found in hypertensive patients with impaired renal function. ${ }^{8}$ This phenomenon may have been responsible for the resurgence of hypertension postoperatively that occurred in three patients.

Resurgence of hypertension occurred only in those patients who had longstanding hypertension. Furthermore, two patients (cases 3 and 5) had severe hypertension, requiring multiple hypotensive drugs. Recurrence of severe hypertension occurred six and eight weeks after operation, after which a regimen of potent antihypertensive drugs was reintroduced and eventually achieved good control. In case 5 the hypertension was particularly difficult to control, and an angiotensin converting enzyme inhibitor was included. This may have a dual advantage of controlling blood pressure and conserving renal function. Stimulation of the renin-angiotensin-aldosterone system may potentiate progressive nephron loss because angiotensin II increases intraglomerular pressure. In experimental renal ablation models with systemic arterial hypertension, intraglomerular hypertension, and progressive renal failure enalapril has been shown to reduce arterial and glomerular capillary pressure to normal and to decrease proteinuria and glomerular damage compared with other antihypertensive drugs. ${ }^{9}$

The pathophysiology of bilateral obstructive nephropathy due to bladder outflow obstruction and its relation to hypertension are poorly understood. Dilatation of the upper urinary tract may be due to raised bladder wall tension and the oblique passage of the

TABLE I-Changes in diastolic blood pressure before and after transurethral resection of prostate

\begin{tabular}{|c|c|c|c|c|c|c|c|c|c|}
\hline \multirow{3}{*}{$\begin{array}{l}\text { Case } \\
\text { No }\end{array}$} & \multirow{3}{*}{$\begin{array}{c}\text { Age } \\
\text { (years) }\end{array}$} & \multirow{3}{*}{$\begin{array}{l}\text { Duration of hypertension } \\
\text { and treatment given }\end{array}$} & \multicolumn{5}{|c|}{ Diastolic blood pressure (mm Hg) } & \multirow{3}{*}{$\begin{array}{l}\text { Duration of } \\
\text { follow up } \\
\text { (years) }\end{array}$} & \multirow[b]{3}{*}{ Postoperative treatment } \\
\hline & & & \multirow[b]{2}{*}{ Preoperative } & \multicolumn{3}{|c|}{ Postoperative } & \multirow[b]{2}{*}{ At last clinic attendance } & & \\
\hline & & & & 1 Week & 3 Months & 12 Months & & & \\
\hline 1 & 50 & 3 Weeks. No treatment & 110 & 80 & 90 & 95 & 85 & 2 & No treatment \\
\hline 2 & 66 & $\begin{array}{l}4 \text { Years. Methyldopa } 1 \mathrm{~g} / \text { day, } \\
\text { cyclopenthiazide }\end{array}$ & 107 & 80 & 80 & 100 & 85 & 5 & After 16 months atenolol $100 \mathrm{mg} /$ day \\
\hline 3 & 70 & $\begin{array}{l}2 \text { Years. Acebutolol } 200 \mathrm{mg} / \mathrm{day} \text {, } \\
\text { frusemide } 40 \mathrm{mg} / \text { day }\end{array}$ & 110 & 70 & 120 & 115 & 80 & 6 & $\begin{array}{l}\text { After } 6 \text { weeks acebutolol } 400 \mathrm{mg} / \text { day, } \\
\text { frusemide } 40 \mathrm{mg} / \text { day, minoxidil } \\
45 \mathrm{mg} / \text { day }\end{array}$ \\
\hline 4 & 63 & 2 Weeks. No treatment & 100 & 85 & 80 & 80 & 80 & 1 & No treatment \\
\hline 5 & 64 & $\begin{array}{l}7 \text { Years. Methyldopa } 1 \mathrm{~g} / \mathrm{day} \text {, } \\
\text { verapamil } 240 \mathrm{mg} / \mathrm{day} \text {, } \\
\text { frusemide } 40 \mathrm{mg} / \mathrm{day}\end{array}$ & 115 & 54 & 130 & 110 & 110 & 2 & $\begin{array}{l}\text { After } 8 \text { weeks enalapril } 40 \mathrm{mg} / \text { day, } \\
\text { frusemide } 40 \mathrm{mg} / \text { day, nifedipine } 80 \\
\mathrm{mg} / \text { day, minoxidil } 20 \mathrm{mg} / \text { day }\end{array}$ \\
\hline 6 & 59 & 1 Week. Labetalol $1200 \mathrm{mg} / \mathrm{day}$ & 120 & 80 & 85 & 85 & 90 & 8 & No treatment \\
\hline
\end{tabular}




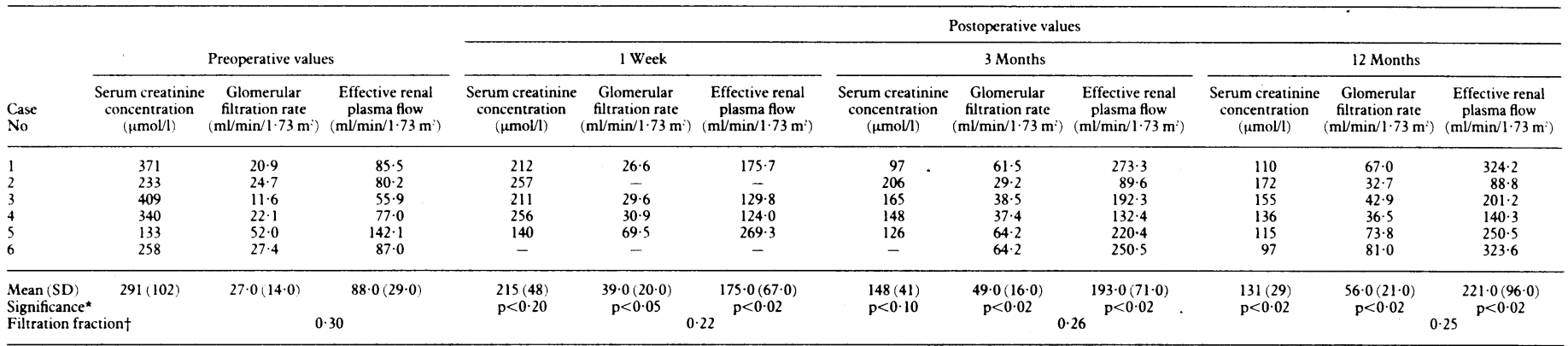

ureter through hypertrophied detrusor muscle. Renal pelvic pressure is consistently lower than bladder pressure, so that back pressure cannot adequately explain upper tract dilatation. ${ }^{10}$ The serum creatinine concentration is raised when intravesical pressure exceeds $25 \mathrm{~cm}$ of water. ${ }^{\prime}$ Lowering intravesical pressure by surgical treatment of bladder outflow obstruction produced a substantial surge in the glomerular filtration rate and effective renal plasma flow after one week, and continued improvements in these values were seen up to a year postoperatively. The time course of these changes is likely to reflect gradual and prolonged recovery from the pathological consequences of obstructive nephropathy. They occurred in patients who had been rendered normotensive postoperatively as well as in those who had developed resurgence of hypertension. The patient given enalapril (case 5) showed good recovery of renal function, but we could not be certain that this drug had contributed.

The prevalence of secondary hypertension accompanying high pressure chronic retention is not known. Any man over 50 who develops hypertension is a candidate for investigation. The aetiology of this form of hypertension is not understood, and various factors such as volume expansion, high renin state, impaired renal function, and loss of renomedullary vasoactive substances may be important. Surgery for prostatic outflow obstruction, together with antihypertensive drugs when required, will control hypertension and allow substantial recovery of renal function.

We are grateful to Mr M B Rose and Mr K C Vaughton for urological assessement and treatment, and Mrs Goldie Williams for secretarial work.

1 George NJR. Lower urinary tract obstruction-obstructive and functiona abnormalities I. In: O'Reilly PH, ed. Obstructive uropathy. Berlin: SpringerVerlag, 1986:235-73.

2 George NJR, O'Reilly PH, Barnard RJ, Blacklock NJ. High pressure chronic retention. Br Med f 1983;286:1780-3.

3 Jones DA, George NJR, O'Reilly PH, Barnard RJ. Reversible hypertension associated with unrecognised high-pressure chronic retention of urine. Lancet 1987; ; 1052-4.

4 Morgan WD, Birks JL, Sivyer A, Ghose RR. An efficient technique for the simultaneous estimation of GFR and ERPF, involving a single injection an two blood samples. Int $\mathrm{J}$ Nucl Med Biol 1977;iv:79.

5 Rascoff JH, Golden RA, Spinouritz BS, Charytan C. Non-dilated obstructive nephropathy. Arch Intern Med 1983;143:696-8.

6 O'Reilly PH, Brooman PJC, Farah NB, Mason GC. High-pressure chronic retention, incidence, aetiology and sinister implications. Br $\mathcal{F}$ Urol 1986;58: 646-64.

7 Belman AB, Kropp KA, Simon NM. Renal-pressor hypertension secondary to unilateral hydronephrosis. $N$ Engl f Med 1968;278:1133-6.

8 Brod J, Bahlmann J, Cachovan M, Hubrick W, Pretschner PD. Mechanism for the elevation of blood pressure in human renal disease. Hypertension 1982;4:839-44.

9 Anderson S, Renake HG, Brenner BM. Therapeutic advantage of converting enzyme inhibitors in arresting progressive renal disease associated with systemic hypertension in the rat. $\mathcal{F}$ Clin Invest 1986;77:1993-2000.

10 Holden D, George NJR, Richards D, Barnard RJ, O'Reilly PH. Rena pelvic pressures in chronic human obstructive uropathy. Br $\mathrm{f}$ Urol 1984;56:565-71.

(Accepted 31 March 1989)

\section{ANY QUESTIONS}

What is the rationale for taking aspirin at a low dose to prevent strokes? Is the mechanism of action similar to that of non-steroidal anti-inflammatory drugs, and if so is there any point in giving aspirin to people taking these drugs?

Aspirin exerts its antithrombotic effect by inhibiting the enzyme cyclooxygenase and thus the formation of thromboxane $A_{2}$, which produces platelet aggregation. This inhibition is caused by irreversible acetylation of the enzyme, and the effect of a single dose of aspirin may last for several days, independent of any circulating aspirin. The effect occurs at low doses of aspirin. Larger doses also inhibit vascular endothelial cyclo-oxygenase and thus the production of prostacyclin, which has antiaggregatory properties. In theory, therefore, small doses of aspirin should be more effective than large doses, but this has yet to be shown to be of clinical importance.

Non-steroidal anti-inflammatory drugs also inhibit cyclo-oxygenase and thus platelet aggregation, but the effect is reversible and persists only while the drug is present in sufficient concentration in the blood. Individual nonsteroidal anti-inflammatory drugs differ in both the degree and the duration of inhibition of platelet aggregation that they produce. ${ }^{12}$ The duration of effect is related to the plasma half life and would probably be increased by the use of sustained release preparations of the shorter acting drugs.

I do not know of any studies of the antithrombotic effects of nonsteroidal anti-inflammatory drugs in relation to prophylaxis against strokes. Presumably some non-steroidal anti-inflammatory drugs would have an antithrombotic effect if taken in sufficient dose and frequently enough to maintain plasma concentrations at the level required for appreciable inhibition of platelet aggregation. For many patients taking these drugs, however, inhibition of platelet aggregation may be intermittent and insufficient to have a clinically important antithrombotic effect.- LINDA BEELEY, consultant clinical pharmacologist, Birmingham

1 Cronberg S, Wallmark E, Soderberg I. Effect of platelet aggregation of oral administration of 10 non-steroidal analgesics to humans. Scand $\mathcal{f}$ Haematol 1984;33:155-9.

2 Longenecker CL, Swift A, Bowen RT, Bevers BJ, Shak AK. Kinetics of ibuprofen effects on platelet and endothetial prostanoid release. Clin Pharmacol Ther 1985;37:343-8.

\section{Are there any health hazards for those who work in food smoking departments?}

A search of the literature yields little useful information on this topic. Fish is smoked with wood smoke: traditionally oak has been used, but other woods and sawdust are often now used. The incomplete combustion of such organic material may produce several potentially harmful products of pyrolysis. Formaldehyde and acrolein are irritants and may cause soreness of the eyes and respiratory tract and, perhaps, a chronic cough if exposure is continuous. Polycyclic aromatic hydrocarbons may also be produced and tend to condense on to airborne particulates such as soot. Many of these are known or suspected human carcinogens.' Modern kilns are, however, believed to produce smaller quantities than older types. Some fish, such as herring and haddock, may be coloured with a dye before smoking. Some of these dyes are suspected animal carcinogens, but there is no evidence that workers handling them are at risk. Employees should not be exposed to smoke if this is reasonable and practicable. Otherwise, they should be provided with appropriate respiratory protective equipment. - A R SCOTT, senior employment medical officer, Nottingham

I Sollenberg J. Polycyclic aromatic hydrocarbons. In: Tarmeggiani L, ed. Encyclopaedia of occupational health and safety. Geneva: International Labour Office, 1983:1755-9. 